\title{
A Study of Chinese Collegiate Attitudes toward Physical Education
}

\author{
Howard Z. Zeng ${ }^{1}$, Yu Wang ${ }^{2} \&$ Xiaolin Wang ${ }^{3}$ \\ ${ }^{1}$ Department of Kinesiology, Brooklyn College of the City University of New York, New York, USA \\ ${ }^{2}$ Department of Physical and Health Education, Northeast Normal University, China \\ ${ }^{3}$ Department of Physical Education, Hubei Engineering University, China \\ Correspondence: Howard Z. Zeng, Department of Kinesiology, Brooklyn College of the City University of New \\ York, New York, USA.
}

Received: October 12, 2015

Accepted: November 23, 2015

Online Published: March 25, 2016

doi:10.5430/irhe.v1n2p1

URL: http://dx.doi.org/10.5430/irhe.v1n2p1

\begin{abstract}
This study examined 1,460 (712 males, 748 females) undergraduate students' attitudes towards physical education (ATPE) from four Chinese colleges/universities. These studies were conducted using the questionnaire of college students' ATPE (QCSATPE) while differences in the participants' ATPE in relation to their gender and major were also examined. The main part of the QCSATPE consists of 20 factors/items regarding college students' ATPE with a 5-point Likert like scale. Data analyzing techniques included descriptive statistics and a 2 × 2 (Gender [males, females] x Majors [nature science, social science]) multivariate analysis of variance (MANOVA). Main findings included: 1) some factors/items scored higher and had more impact on the participants' ATPE; e.g. "physically fit and strong," "good body shape," and "feelings about PE class." 2) Significant difference exists in 'Gender' and "Majors' variables, wherein 28 out of 40 comparisons reached significant differences $(p<.05)$. In brief, the college students' ATPE in the current investigation was not so positive. Gender and majors are two important aspects that form and impact on their ATPE differently whereas the males scored higher than those of females, and the students of nature sciences scored higher than students of social sciences.
\end{abstract}

Keywords: attitudes, gender, majors, physically fit, healthy lifestyle

\section{Introduction}

There has been a tremendous increase in the body of knowledge pertaining to the attitudes of young people toward physical education (PE) and physical activity (PA) participation since 1990. The increased interest in this topic of research may be attributed to the influence of attitudes toward further participation in PA after school (Papaioannou, 1994; Subramaniam \& Silverman, 2002; 2007; Tannehill, \& Zakrajsek, 1993; Zeng, Leung, \& Hipscher, 2011) and out of school that is associated with students' achievements in athletic activities (Lee, 1997; Rikard \& Banville, 2006; Subramaniam \& Silverman, 2002; 2007). Stucky-Ropp and DiLorenzo (1993) reported that enjoyment in PE and PA appears to positively associate with children at all school levels, while other researchers reported that young people who have hated PE classes may choose to stop participating in PA in their daily life (Carlson, 1994; 1995; Chung \& Phillips, 2002; Dunlavy, 2008; Portman, 1995). Krouscas (1999) reported that positive attitudes toward physical education (ATPE) decline among middle school students; this trend was more apparent for girls than for boys. Silverman and Subramaniam (1999) indicated that students tend to participate continually in PA when they have fun and enjoy it.

According to a review of literature on student's ATPE and PA, Solmon (2003) summarized that students' characteristics and contextual factors are two major factors that relate to students' ATPE and PA participation. Students' characteristics refer to their age, gender, and skills in sports. Contextual factors include the quality of PE programs and accessibility of after school PE or PA programs. As more and more people realize a healthy lifestyle is important for their success, happiness and quality of life, the importance of having a high quality PE experience in one's college education is apparent. Moreover, researchers in the fields of PA and health education have found evidence supporting that PA can strengthen individuals' muscles and immune system; it also helps prevent diseases such as cardiovascular disease, diabetes, and obesity (Dunlavy, 2008; Hagger, Chatzisarantis, \& Biddle, 2002; Lee, 2004; Raitakari, Juonala, \& Viikari, 2005; Sacker, 2005; U.S. DHHS, 2000). 
Since the year of 2000, many research studies have been involved in peoples' physical exercise status and their health-related fitness and found that physical inactivity is one of the primary reasons for losing body functions (Chase, 2000; Dunlavy, 2008; Lester, 2007; Olafson, 2002; U.S. DHHS, 2000). Researchers also found that PE and regular physical exercise can effectively improve health-related fitness elements such as lower body fat, lower blood pressure, improve strength, build bone density, and lower cholesterol (e.g. McKenzie, 2003; Sacker, 2005; U.S. DHHS, 2000). According to U.S. DHHS (2000), people who do physical exercise regularly live longer and have lower premature death rates than those who do not. Thankfully, PE programs have been recognized as ideal environments to raise young people's health-related knowledge, essential physical skills and species of activity; eventually those young people will form a positive ATPE and establish an active lifestyle (Chase, 2000; Dunlavy, 2008; Iverson, McKenzie \& Sallis, 1996; Lee, 2004; Raitakari, Juonala, \& Viikari, 2005). Additionally, as Olafson (2002) and Dunlavy (2008) pointed out, the key reasons for young people who choose to not participate in regular PA are due to their negative ATPE and relate to the following excuses: disliking PA, having unhappy experience(s) in PE, lack of time, lack of money, or no transportation tools available, and etc.

\subsection{Theoretical Framework on the Study of Attitudes toward Physical Education}

According to Katz (1960), attitudes serve individuals in the following four aspects: (a) Guide behavior toward valued goals and away from aversive events; (b) help to manage and simplify information; (c) allow individuals to communicate information about their personality and values; (d) protect individuals from unacceptable or threatening thoughts, urges, and impulses. Biddle and Chatzisarantis (1999) indicated that the link between attitudes and behavior has received much attention; and people believe that attitudes are influential to behavior. Theoretically, this relationship is not singular, but it is rather multidimensional. With this concern, Biddle and Chatzisarantis further described that in predicting behavior, attitudes are only part of a more complex decision making process where other factors, such as: values, beliefs, intentions, perceptions of control can also be the dimensions of influence; and all these dimensions form the attitude-behavior relationships. Moreover, Rikard and Banville (2006) stated that attitudes are born from beliefs that one has about himself or herself and things. Attitudes shape one's behaviors in many ways and determine one's involvement in one's daily activities.

In explaining the relationship among attitudes, intentions, and future behavior, Ajzen and Fishbein (1980) developed a theoretical framework, named "Theory of Reasoned Action;" it asserts that human action is determined by intention that is influenced by attitudes and social norms; while attitudes are influenced by beliefs and values; and then, social norms are influenced by the beliefs of significant others and the motivation to comply with the beliefs of others. The 'Theory of Reasoned Action' implied that the interplay of all these variables are what guide behavior. This theory asserts that attitudes do influence behavior; as a result, researchers in the field of PE have historically examined students' ATPE in the hopes of enhancing students' interest in PE and PA.

Concerning how students' ATPE influence on young people's regular PA participation, many previous researchers have done remarkable works, such as: Figley (1985), Dunlavy (2008), Kreskas (1999), Lee (2004), Luke and Sinclair (1991), Olafson (2002), Sacker (2005), Solmon (2003), Subramaniam and Silverman (2007), and Zeng (2012). In summary, these studies found that teachers' behaviours, contents of the curriculum, class atmosphere, dressing out, self-perception and quality of the PE program possess enormous impacts on students' ATPE. In particular, two previous research studies found the impacts on students' ATPE and sports/activities participation were highly associated with the following three factors in a very consistent way: (a) cultural, including gender, idolizing elite sports figures, body and mind distinctions; (b) social, including family, peers, media, PE and sport experiences, skill level, perceptions of fitness; (c) school, including teachers, curricula, facilities, equipment, and environment (Carlson, 1995; Zeng; 2012).

Regrettably, a large amount of the previous studies were done in K-12 school levels, while an extremely limited amount of studies had been done in college/university level concerning college/university students' ATPE. While a problem has been raised: If we have no idea what the current status of collegiate ATPE is, how can we possibly provide enjoyable and helpful PE courses and PA programs for this extremely important sub-population? Research findings from the topic of PE and health life style have suggested that identifying and understanding the factors that motivate or drive young peoples to take part in physical exercises regularly are critical; while to promote a healthy lifestyle among the young peoples knowing and changing their ATPE are the key aspects (Chung \& Phillips, 2002; Dunlavy, 2008; Hagger, Chatzisarantis, \& Biddle, 2002; Sacker, 2005; Solmon, 2003; Subramaniam \& Silverman, 2007; Zeng, Leung, \& Hipscher, 2011). Students who possess more positive ATPE were reported to be more likely to take part in regular PA outside of schools (Biddle \& Chatzisarantis, 1999; Chung \& Phillips, 2002; Dunlavy, 2008; McKenzie, 2003; Portman, 2003; Sacker, 2005); and demonstrate higher PA amounts / physical exercises loads 
(Chung \& Phillips, 2002; Hagger, Cale, \& Almond, 1995; Liu, Wang, \& Xu, 2008) than those students possess negative ATPE or with less positive ATPE.

\subsection{Purposes}

For the majority of young people, college education would be their last chance to acquire formal physical education that would have long-term impact on their future life. This is why knowing and altering collegiate ATPE possesses significant meaning. The purposes of this study, therefore, were to investigate the current status of collegiate ATPE; get insight into what would be the most important factors that structured and driven collegiate ATPE; examine possible differences concerning participants' ATPE between their gender and majors; and provide meaningful recommendations for changing or maintaining college students' ATPE.

\section{Method}

\subsection{Instrumentation}

Due to no existing questionnaire available for examining collegiate ATPE, we adapted two questionnaires based on a previously validated Physical Education Activity Attitude Scale (Valdez, 1997) and the Physical Education Activity Attitude Scale - using at high school level (Zeng, 2012) into a new questionnaire named as Questionnaire of Collegiate Attitudes toward Physical Education (QCATPE). This questionnaire consists of 20 items concerning collegiate ATPE with a 5-point Likert like scale (from 1 = 'Strong-disagree,' $2=$ 'Disagree,' 3 = 'Some-agree,' 4 = Agree, to 5 = 'Strong-agree'). For example, Item 1 "I enjoy the feeling after I have a very well organized physical education class." Item 7 "Physical exercise is the best way to obtain a youthful looking and agile body." And item 20 "During one's college/university years, physical education has nothing to do with one becoming a successful person in one's later life." (Note. The entire QCSATPE was translated into Chinese and can be found in Appendix A.) The reasons for adapting and using this questionnaire for data collection were due to: a) no existing questionnaire available; b) funding available for this study was very limited, to develop a new questionnaire would cost much of the time and money; c) there were specialists available in the topic of ATPE, they revised the existing questionnaires into one new questionnaire that was specifically fit for using at the college/university level; d) research assistants (they were also professors in the selected colleges/universities) were available for questionnaire distribution and collection.

\subsubsection{Reliability and Validity of the Instrument}

Child (1990) indicated that in order to explore the possible underlying factor structure of a set of measured variables without imposing any preconceived structure on the outcome, the exploratory factor analysis (EFA) is the best solution; hence, the EFA was executed and the results showed: the analysis extracted 7 factors with perfect correspondence to the 20 items with eigenvalues for the factors ranging from 1.78 to 7.89 and structure coefficients from .68 to .93 , the majority of the fitted residuals reached the pre set-up significant difference $(P<.05)$ level as well. For the validation process a pilot test was conducted, it involved 136 respondents in a convenience sample of a college wherein 73 students were from Nature Science and 63 students were from Social Science; minor modifies were made to the contents in some items of the questionnaire, and the order of the questions was also changed. As a result, the QCATPE (Zeng, 2012) contained two parts: Part I - Demographic and general information, containing seven questions that cover participant's general information. Part II - The Factors of ATPE, containing a 'Direction' illustrated that: There are 20 statements about ATPE below, please: read each statement carefully; expresses your feeling about the statement by circling the one choice that you feel is the most appropriate to you, do not spend much time to do so; and respond to all the statements. For the effects of reliability this new questionnaire 10 positive statements were developed and they were arranged in the odder number; that is: the way of scoring has to use 5 for 'Strongly Agree', and 1 for 'Strongly Disagree'; and 10 nagitive statements were developed and they were arranged in the even number; that is: the way of scoring has to use 1 for 'Strongly Agree', and 5 for 'Strongly Disagree'. See the QCATPE (Zeng, 2012) for details.

\subsection{Data Collection Procedures}

The approval documentations for using college/university students as participants for the current survey study were obtain from the institutional review board (IRB). The procedures in using human subjects were as following: a) "Multi-campus IRB Approval Policy". The data collection was take place on the campuses of four selected colleges/universities within a safe environment (e.g. an established or commonly accepted educational setting). b) Obtained permissions from those relative department chairpersons [e.g. from nature science (e.g. Physics, Chemistry, or Mathematics), and from social science (e.g. History or Sociology) at each selected college/university. The data collection was done within a semester, and professors who voluntarily help this survey would administer the 
questionnaires within their classroom settings. No attempt would be made to evaluate their PE programs in these colleges/universities.

\subsection{Participants and Data Analysis}

Approximately 1,980 college/university students were purposefully recruited from four different types of colleges/universities located in the Northeast and Central regions of China. Although the locations were in regions of Northeast and Central of the China, the students were enrolled from nationwide. Moreover, these colleges/universities' campuses were located at urban and suburb areas, and the majors of the participants were from either Nature Science or Social Sciences, thus, the sampling should not have geographical or regional issues. Consequently, 1,460 questionnaires were returned and completed correctly, return rate $=73.73 \%$. Times for delivering, reading and responding the questionnaire need about $15-20$ minutes. Note that, this survey is a volunteer participate activity, the student who decides to participate was required to provide her/his 'Inform Consent Form' before the survey would be given. The participants, therefore, were 1,460 undergraduate students (712 Males, 748 Females; or 707 Nature Science, 753 Social Science; age between 18 to 22, $M_{\text {avrage }}=20.5 \pm 2.78$ ) from four different types of Chinese colleges/universities. The Questionnaire of college-students' ATPE ${ }^{\text {-Chinese Version }}$ (QCATPE ${ }^{-\mathrm{CV}}$, Zeng, 2012) was employed for data collection. This questionnaire consists of 20 items concerning collegiate attitudes towards physical education with a 5-point Likert like scale (from $1=$ 'Strong-disagree' to 5 = 'Strong-agree'; and see the Note in Table as well). Nelson, Thompson, and Silverman (2005) illustrated that survey is a technique of descriptive research that seeks to determine current practices or opinions of a specific population. Surveys can come in the form of a questionnaire, a personal interview or normative survey are three different types of survey. In comparison, questionnaire possesses lower cost, higher efficiency, and less in use times than the other two survey techniques. Data analyses were done by descriptive statistics and a 2 x 2 (Gender [males, females] x Majors [Nature Science, Social Science]) multivariate analysis of variance (MANOVA).

\section{Results}

\subsection{Demographic and General Information}

The demographic and general information of the participants are presented in Table 1 . There was no senior students took part in the current survey. There were 23\% students claimed their fitness are at 'Excellent' level; 25\% students rated their fitness are at 'Good" level; 31\% students believed their fitness are on 'Average' level; and 21\% students considered their fitness are at 'Poor' level. Whereas $15 \%$ rated their ability in sports are 'Excellent'; 19\% rated as 'Good'; 39\% claimed as 'Average'; $15 \%$ thought they are not good at sports and 13\% considered their sports ability belong to 'Poor".

Table 1. Participants' demographic and general information

\begin{tabular}{lll}
\hline \multicolumn{1}{c}{ Question / Items } & Responds and Distribution (\%) & \\
\hline 1. What is your gender? & Male $(712 / 48.8 \%)$ & Female $(748 / 51.2)$ \\
2. Your major belong to? & Nature Science $(707 / 48.4 \%)$ & Social Science $(753 / 51.6 \%)$ \\
3. What status are you as a colleagiate? & Freshman $(438 / 30 \%)$ & Sophomore $(803 / 55 \%)$ \\
& Junior $(219 / 15 \%)$ & Senior $(0 / 0 \%)$ \\
4. Which ethnic group do you belong to? & White/Caucasian $(0 / 0 \%)$ & Black/African American $(0 / 0 \%)$ \\
& Hispanic $(0 / 0 \%)$ & Asian $(1,460 / 100 \%)$ \\
5. How would you rate your body build? & Over Size $(175 / 12 \%)$ & Average Size $(1095 / 75 \%)$ \\
& & Under Size $(190 / 13 \%)$ \\
6. How would you rate your level of fitness? & Excellent $(336 / 23 \%)$ & Good (365 / 25\%) \\
& Average $(453 / 31 \%)$ & Not So Good $(306 / 21 \%)$ \\
7. How would you rate your ability in sports? & Excellent $(219 / 15 \%)$ & Good $(277 / 19 \%)$ \\
& Average $(569 / 39 \%)$ & Not good $(219 / 15 \%)$ Poor $(190 / 13 \%)$ \\
\hline
\end{tabular}

\subsection{Current Status of the Participants' ATPE}

The factors that constructure college/university student' ATPE are presented in Table 2. First, the following five items scored high and possessed higher impact power on participants' ATPE. Those are: Item 5 "It is important to me to keep physically fit and strong" $(\mathrm{M}=4.351 \pm .821)$; Item13 "Have physical education classes and daily physical 
activity during college is essential for one to have a good posture and a sturdy body throughout one's life" ( $\mathrm{M}=$ $4.270 \pm .715$ ); Item 9 "The formation of a positive lifestyle is a person achieves his/her optimal physical and mental functions necessary factor later in life" $(\mathrm{M}=4.235 \pm .764)$; Item 1 "I enjoy the feeling after I have a very well organized physical education class" $(\mathrm{M}=4.209 \pm .794)$; and Item 19 "The values of physical education and activity have scientific bases" $(\mathrm{M}=4.164 \pm .718)$.

Second, the following five items scored lower and possessed less impact power on participants' ATPE. Those are: Item 20 "During one's college/university years, physical education has nothing to do with one becoming a successful person in one's later life"; Item 14 "Being serious about physical education /activities during college is brainless"; Item 18 "In my college/university, physical education programs have little to offer"; Item 10 "Most college students get all the physical exercise they need just doing their daily work"; and Item 2 "Based upon my experience, physical education is not a valuable subject". The mean score for these five items were from $M=2.738$ to $M=2.916$; basically that was fall in denied or refuse category. Furthermore, the rest 10 items on Table 2 scored medium to higher. The mean score for these 10 items were from $M=2.921$ to $\mathrm{M}=4.063$ which was fall in 'some agree' or 'agree' category.

\subsection{Factors / Elements That Constructure University Students' ATPE}

The Factors / Elements that constructure the participants' ATPE are presented in Table 2.

Table 2. Factors / elements that constructure college/university students' ATPE $(N=1,460$, Male $=712$, Female $=$ 748 ; or Nature Science $=707$, Social Science $=753 ; M_{\text {age }}=20.5 \pm 2.50$ ).

\begin{tabular}{|c|c|}
\hline Items & $M(S D)$ \\
\hline E1. I enjoy the feeling after I have a very well organized physical education class. & $4.209(0.794)$ \\
\hline E2. Based upon my experience, physical education is not a valuable subject. & $2.916(1.345)$ \\
\hline E3. Physical education / activity provide a great relief from my daily life. & $3.903(0.938)$ \\
\hline E4. Physical education courses should be eliminated from college/university curricula. & $2.936(1.458)$ \\
\hline E5. It is important to me to keep physically fit and strong. & $4.351(0.821)$ \\
\hline E6. Physical exercises are only beneficial to the people who are already in good body shape. & $2.908(1.420)$ \\
\hline E7. Physical exercise is the best way to obtain a youthful looking and agile body. & $4.063(0.865)$ \\
\hline E8. I believe physical education / activity is necessary but I don't much care about it. & $2.921(1.169)$ \\
\hline $\begin{array}{l}\text { E9. The formation of a positive lifestyle is a person achieves his/her optimal physical and mental } \\
\text { functions necessary factor later in life. }\end{array}$ & $4.235(0.764)$ \\
\hline E10. Most college students get all the physical exercise they need just doing their daily work. & $2.913(1.139)$ \\
\hline E11. For me physical education/activity classes are just as important as other academic classes. & $3.815(0.985)$ \\
\hline E12. During college, there are more important things than becoming a physically educated person. & $2.947(1.087)$ \\
\hline $\begin{array}{l}\text { E13. Have physical education classes and daily physical activity during college is essential for one to } \\
\text { have a good posture and a sturdy body throughout one's life. }\end{array}$ & $4.270(0.715)$ \\
\hline E14. Being serious about physical education /activities during college is brainless. & $2.749(1.348)$ \\
\hline E15. Having daily physical exercise is one of the most important things in my collegiate life. & $3.693(0.980)$ \\
\hline E16. Staying in good body shape takes more effort than it is worth. & $3.126(1.122)$ \\
\hline E17. No other discipline is as useful as physical education for one's well-being. & $3.105(1.092)$ \\
\hline E18. In my college/university, physical education programs have little to offer. & $2.758(1.238)$ \\
\hline E19. The values of physical education and activity have scientific bases. & $4.164(0.718)$ \\
\hline $\begin{array}{l}\text { E20. During one's college/university years, physical education has nothing to do with one becoming a } \\
\text { successful person in one's later life. }\end{array}$ & $2.738(1.163)$ \\
\hline Grand Sum $=67.930$ & Grand Mean $=3.396$ \\
\hline
\end{tabular}

Note. a) Positive statements are number 1, 3, 5, 7, 9, 11, 13, 15, 17, and 19; when count for scoring the following manner should be used: Strongly Agree =5; Agree =4; Some-agree = 3; Disagree =2; and Strongly Disagree =1.

b) Negative statements are number 2, 4, 6, 8, 10,12,14,16,18, and 20; when count for scoring the following manner should be used: Strongly Agree =1; Agree =2; Some-agree = 3; Disagree =4; and Strongly Disagree =5. 


\subsection{The Participants' Differences ATPE between Their Gender and Majors}

For the purpose of examine whether or not differences exist between gender and majors of the participants' ATPE in the same time, the a 2 x 2 (Gender [males, females] x Majors [nature science score, social-science]) MANOVA was employed; and the results revealed that: significant difference was found in both 'Gender' aspect $(p<.00), \Lambda=.961$, $F=2.885$; and 'Majors' aspect $(p<.000), \Lambda=.915, F=6.683$ (see Table 3 ).

Table 3. The 2 (Gender) $\times 2$ (Majors) Multivariate Test (MANOVA) ${ }^{\mathrm{a}}$ for comparing ATPE of the participants' ATPE

\begin{tabular}{llllll}
\hline Source & $\begin{array}{l}\text { Wilks' } \\
\text { Lambda }\end{array}$ & $F$ & $\begin{array}{l}\text { Hypo } \\
d f\end{array}$ & $\begin{array}{l}\text { Error } \\
d f\end{array}$ & $P$ \\
\hline Gender & .961 & $2.885^{\mathrm{b}}$ & 20.000 & 1437.000 & .000 \\
Majors & .915 & $6.683^{\mathrm{b}}$ & 20.000 & 1437.000 & .000 \\
\hline
\end{tabular}

Note. ${ }^{\text {a }}$ Design: Intercept + gender + E-level + B-Colors;

${ }^{\mathrm{b}}$ Exact statistic

\subsection{The Differences among the Gender and Majors Factors: Findings on Participants' ATPE Scores}

According to the research design, after significant differences effects were found, an 2 x 2 (Gender [males, females] $x$ Majors [Nature Science, Social Science]) MANOVA Test for determine where and what the Students' ATPE among their gender and majors factors was conducted; and the findings were present in Table 4.

Table 4. Descriptive statistics and comparisons of university students' ATPE ( $N=1,460,712$ Males, 748 Females; or 701 Nature sciences, 753 Social sciences)

\begin{tabular}{lllll}
\hline Items & \multicolumn{2}{c}{ Gender $-\boldsymbol{M}(\boldsymbol{S D})$} & or & \multicolumn{2}{c}{ Majors -- $\boldsymbol{M}(\boldsymbol{S D})$} \\
& Males $(712)$ & Females $(748)$ & Nature science $(707)$ & Social science $(753)$ \\
\hline E1 & $4.272(0.752)$ & $4.160(0.841)$ & $4.275(0.779)$ & $4.150(0.804)^{*}$ \\
E2 & $2.925(1.357)$ & $2.907(1.317)$ & $3.058(1.413)$ & $2.783(1.265)^{*}$ \\
E3 & $4.019(0.918)$ & $3.792(0.944)^{* *}$ & $4.025(0.907)$ & $4.248(0.893)^{*}$ \\
E4 & $3.048(1.525)$ & $2.933(1.409)$ & $3.048(1.525)$ & $2.831(1.385)^{*}$ \\
E5 & $4.475(0.721)$ & $4.231(0.886)^{* *}$ & $4.461(0.721)$ & $3.545(0.938)^{* *}$ \\
E6 & $2.915(1.423)$ & $2.902(1.417)$ & $3.067(1.452)$ & $2.759(1.373)^{*}$ \\
E7 & $4.186(0.770)$ & $3.946(0.932)^{*}$ & $4.162(0.805)$ & $3.972(.909)^{*}$ \\
E8 & $2.792(1.171)$ & $3.044(1.155)^{*}$ & $2.854(1.144)$ & $2.984(1.190)^{*}$ \\
E9 & $4.279(0.751)$ & $4.193(0.775)$ & $4.266(0.758)$ & $4.207(0.769)$ \\
E10 & $2.859(1.177)$ & $2.965(1.100)$ & $2.935(1.196)$ & $2.984(1.083)$ \\
E11 & $4.023(0.892)$ & $3.617(1.028)^{* *}$ & $3.967(0.923)$ & $3.665(1.018)^{*}$ \\
E12 & $2.876(1.084)$ & $3.014(0.945)^{*}$ & $2.884(1.084)$ & $3.006(1.087)^{*}$ \\
E13 & $4.342(0.675)$ & $4.202(0.744)^{*}$ & $4.315(0.698)$ & $4.228(0.728)^{*}$ \\
E14 & $2.803(1.305)$ & $2.697(1.386)^{*}$ & $2.929(1.355)$ & $2.580(1.320)^{* *}$ \\
E15 & $3.855(0.907)$ & $3.540(1.021)^{* *}$ & $3.828(0.934)$ & $3.571(1.005)^{* *}$ \\
E16 & $2.906(1.188)$ & $3.335(1.130)^{*}$ & $2.836(1.172)$ & $3.984(1.118)^{* *}$ \\
E17 & $3.143(1.222)$ & $3.069(1.063)$ & $3.086(1.131)$ & $3.123(1.055)$ \\
E18 & $2.682(1.215)$ & $2.831(1.256)^{*}$ & $2.718(1.239)$ & $2.796(1.236)$ \\
E19 & $4.238(0.597)$ & $4.093(0.811)^{* *}$ & $4.226(0.613)$ & $4.106(0.800)^{*}$ \\
E20 & $2.726(1.158)$ & $2.750(1.168)$ & $2.799(1.185)$ & $2.681(1.140)^{*}$ \\
\hline
\end{tabular}

Note. ${ }^{*}=$ Significant at $\mathrm{p}<.05$. Level; $* *=$ Significant at $\mathrm{p}<.01$ level. There are 40 comparisons in total, wherein 28 comparisons showed significant differences at $\mathrm{p}<.05$ or $\mathrm{p}<.01$ level. E1 to E20 Represent 20 different "Attitude towards" elements - see Table 2 for details.

As showed in Table 4, twenty-eight out of 40 comparisons from the 'Gender' and 'Majors' aspects reached significant difference at ether $p<.05$ or $p<.01$ level, e.g. on Item E3 "Physical education / activity provide a great 
relief from my daily life", male scored vs. female scored ( $M=4.019$ vs. 3.792), social science scored $(M=4.284)$ vs. nature science scored $(M=4.025)$. Item 5 "It is important to me to keep physically fit and strong", male scored $(M=$ $4.475)$ vs. female scored $(M=4.231)$, nature science scored $(M=4.461)$ vs. social science scored $(M=3.545)$. Item E7 "Physical exercise is the best way to obtain a youthful looking and agile body", male scored $(M=4.186)$ vs. female scored $(M=3.946)$, nature science scored $(M=4.162)$ vs. social science scored $(M=3.972)$. Item E15 "Physical exercise is one of the most important things in my collegiate life", male scored $(M=3.855)$ vs. female scored $(M=3.540)$, nature science scored $(M=3.828)$ vs. social science scored $(M=3.571)$.

In contract, there were also a few items females scored higher than those of males, e.g. on Item E8 "I believe physical education / activity is necessary but I don't much care about it" female scored $(M=3.044)$ vs. male scored $(M=2.792)$; Item E 12 "During college, there are more important things than becoming a physically educated person" female scored $(M=3.014)$ vs. male scored $(M=2.876)$; tem E18 "In my college/university, physical education programs have little to offer" female scored $(M=2.831)$ vs. male scored $(M=2.682)$.

However, all the participant, regardless their gender or majors their scores on the following statements / items were at no significant difference $(p>.05)$ level or they gave a very similar responses; such items were: Item E1 "I enjoy the feeling after I have a very well organized physical education class"; Item E 9 "The formation of a positive lifestyle is a person achieves his/her optimal physical and mental functions necessary factor later in life"; Item E10 "Most college students get all the physical exercise they need just doing their daily work"; and Item E17 "No other discipline is as useful as physical education for one's well-being" with all genders and majors".

\section{Discussion}

The current study examined the status of the college students' ATPE and found out what the important factors have influenced on their ATPE; meanwhile those possible differences between the participants' ATPE relate to their gender and majors were also confirmed. The current status of the participants' ATPE presented in the results section indicated that the overall mean score from the 20 items was 67.93 out of the full score $(100.00)$ or (the Grand Sum = 67.93, and the Grand Mean =3.39); which told this sample participants' ATPE was not so positive and have a lots of room for enhancing. Reasons are simple, because attitudes shape one's behaviors and determine one's involvement in her/his daily activities; the same reason can be applied to the participation of regular and daily PA (Rikard \& Banville, 2006). With this level of attitudes toward, it is not hard to image those students who scored under this Grand Mean score (3.39) would not go to the fields or gyms have their physical exercise regularly.

To help these students enhancing their ATPE, useful and meaningful strategies and tips have provided from the previous studies on the topic of ATPE; such as: Subramaniam and Silverman (2002) indicated that students' positive ATPE associated with enjoyment, perceived usefulness of the curriculum, and a sense of belongingness. Chen and Darst (2001) had specified that curriculum with situational interests, such as those requiring students to analyze and design offensive and defensive strategies, can foster students' interests in physical activity. Rink (2006) stated that a learning environment that promotes personal meaning is considered to be important to the development of positive attitudes. Hagger, Chatzisarantis, and Biddle (2002) identified that students are also likely to become more positive toward physical activity if they are in a learning environment that makes them comfortable and confident. Dunlavy (2008) suggested that university PE faculty should educate their students the importance of moderate and vigorous physical activities and teach them an active lifestyles could prevent one become overweight. Additionally, Zeng, Leung and Hipscher (2011) recommended that: To enhance positive ATPE and promote PE experiences for students, the following things need to be done: a) increase the participation of PE teachers during their classes in the physical activities (role model and leading by example); b) implementing multiple teaching styles in order to meet diverse learners' needs and characters; c) offer variety of sports or physical activities for students to choose; and d) consider students' gender features and plan lessons or provide exercise programs suitable for their gender features.

For the current study, as to which specific aspects need to work on and the PE programs can help with those concern, we would like to make the discussion as below: Regarding the differences of the participants' ATPE between their gender, the big picture was: males possess obviously higher positive ATPE than those of the females [or males scored higher than female on the QCATPE ${ }^{-\mathrm{CV}}$ (Zeng, 2012)]; that evidenced by the males scored significantly higher than the females on 8 items (E3, E5, E7, E11, E13, E14, E15, \& E19), whereas, females scored significantly higher than those of male on only 4 items (E8, E12, E16, \& E18). Additionally, the rest 8 items (E1, E2, E4, E6, E9, E10, E17, \& E20) males and females scored similar (see Table 4 and Table 2 for details).

Specifically males had much stronger feeling on the following expressions: "Physical education / activity provide a great relief from my daily life"; "It is important to me to keep physically fit and strong"; "For me physical education/activity classes are just as important as other academic classes"; "Having daily physical exercise is one of 
the most important things in my collegiate life". In contract, females were in favor on the following expressions: "I believe physical education / activity is necessary but I don't much care about it", "During college, there are more important things than becoming a physically educated person", and "Staying in good body shape takes more effort than it is worth". With tis kind of attitudes / believe it is hard to imagine they would take part in PE and PA regularly.

The findings of the currents study are consistent with the previous studies by Specifically, Greenwood and Stillwell (2001), Colley, et al., (1994), and Parkhurst (2000) reported that boys were reported to have more positive attitudes than girls toward physical activities; however, our findings are different from the finding by Subramanian and Silverman (2002), they reported that did not find gender difference in ATPE between boys and girls.

With regard to of the differences of the participants' the ATPE between their majors, the big picture was: Nature science possess obviously higher positive ATPE than those of the Social science [or Nature science scored higher than Social science on the QCATPE ${ }^{-\mathrm{CV}}$ (Zeng, 2012)]; that evidenced by the Nature science scored significantly higher than the Social science on 12 items (E1, E2, E4, E5, E6, E7, E11, E13, E14, E15, E19, \& E20), whereas, Social science scored significantly higher than those of Nature science on only 4 items (E3, E8, E12, \& E16). Additionally, the rest 4 items (E9, E10, E17, \& E18) both Nature science and Social science scored similar (see Table 4 and Table 2 for details). Particularly Nature science had much stronger feeling on the following expressions: "Physical education courses should be eliminated from college/university curricula"; "Having daily physical exercise is one of the most important things in my collegiate life"; "Having daily physical exercise is one of the most important things in my collegiate life". But disagree on the statements of "Being serious about physical education /activities during college is brainless"; "Staying in good body shape takes more effort than it is worth"

In contrast, although the Social science believed: "Physical education / activity provide a great relief from my daily life", but they were more tend to these: "Staying in good body shape takes more effort than it is worth" "I believe physical education / activity is necessary but I don't much care about it", and "During college, there are more important things than becoming a physically educated person". With this kind of attitudes it is hard to imagine they would take part in PE and PA daily / regularly. By this point, we really see there are big differences between the two majors in nature. With regard to the comparison between the differences of the majors, the findings above were relatively new, which means we provided a set of quantitative data to the topic of relationship between ATPE and participants' majors, because there is no findings available from the previous study in this concern.

\subsection{Limitations}

The present study explored Chinese collegiate ATPE using a newly adapted questionnaire - the Questionnaire of ATPE (QCATPE) provide a set of quantitative data with regard to Chinese collegiate ATPE. Despite we obtained unique findings, a few limitations of the present study should be acknowledged. The first limitation is the sample size, that is, no matter how to explain it, the 1,460 participants for the topic of collegiate ATPE is still a quite small sample size. The second limitation is due to lack of funding; the current study did not able to implement the third part of the questionnaires -- the "Questions about Your Sport and Activity Preference". The most important questions in this part are: 1) what types of sports do you like the most? (Answers included 'Team sports', 'Individual sports' and 'Dual Game Sports'. 2) What type of physical activity do you like the most? (Answers included a list of the activities, e.g. 'Aerobic Exercises', 'Physical Conditioning', 'Martial Arts' 'Out Door Adventure'; the participant can circle on the one she/he like the most as her/his answer. Future studies should try every effort to enlarge the size of the sample and their Regional / State coverage. The third part in the questionnaire should be included in the survey so that the new study able to acquires the information in the participants' "Sport and Activity Preference" that will enable researchers make meaningful comparisons with those of the previous studies regarding the concern of college students" "Sport and Activity Preference".

\subsection{Conclusions and Recommendations}

\subsubsection{Conclusions}

In conclusion, first, this study established an initial set of data from the 1,460 college students' from four different colleges/universities of China regard to their ATPE. In general, participants in this sample's ATPE are slightly under the positive status, which provided feedback for educators or professionals in their regions. For examples: (a) in order for college students in their college years establishing a positive ATPE, set up new rules to have college students participate in PA regularly are necessary; (b) in order to form a health active lifestyle eventually, many works and solutions are need to be done by both of the educators and students. Second, gender and majors differences do exist, in particular the males have more positive ATPE than those of the females; the collegiate in 
Nature Science majors tend to have more positive ATPE than those of the collegiate in Social Science majors. Third, regardless the participants' gender and majors, things relate to the features of PE, PA and health lifestyle, the participants do respond in a very similar manner, which reflected these college students do possess necessary knowledge and concepts about physical education, physical activity and health lifestyle. As to why some of the participants respond to PE, participate in daily PA and an active lifestyle were not so positive, that may relate to these participants are facing many other new challenges in their college/university life.

\subsubsection{Recommendations}

Based on the findings above, our recommendations are: 1) Authorities must recognize that college/university students participate in PE and daily PA are necessary. In order to accomplish this goal, the necessary human and material resources must be guaranteed, so that college/university students can have a better environment to participate in daily physical exercise. 2) Reform PE curricula and PA programs, so that the college/university students can really enjoy, receive usefulness from the update curricula and PA programs, and have a sense of belongingness as well. 3) Earnestly improve college/university's PE and PA teaching-learning environment that will impact on the promotion and development college/university students' ATPE and PA. 4) Increase the participation of PE teachers whenever they teach a PE lesson or organize a PA program (effect of role model). 5) Implementing multiple teaching styles in order to meet diverse learners' needs and features (e.g. The Spectrum of teaching styles in physical and health education settings). 6) Offer variety of sports or PA for students to choose from (i.e. alignment with the needs of the diverse learners. 7) Consider students' gender features and provide exercise programs that are suitable for their gender and majors characteristics.

\section{References}

Adams, R. S. (1963). Two scales for measuring attitude toward physical education. Research Quarterly, 34, 91-94.

Ajzen, I., \& Fishbein, M. (1980). Understanding attitudes and predicting social behavior. Englewood Cliffs, NJ: Prentice-Hall.

Biddle, S. J. H., \& Chatzisarantis, N. (1999). Motivation for a physically active lifestyle through physical education. In Y. V. Auweele, F. Bakker, S. Biddle, M. Durand, \& R. Seiler (Eds.), Psychology for physical educators (pp. 5-26). Champaign, IL: Human Kinetics.

Carlson, T. B. (1994). Why students hate, tolerate, or love gym: A study of attitude formation and associated behaviours in physical education. Unpublished doctoral dissertation, University of Massachusetts, Amherst, MA.

Carlson, T. B. (1995). We hate gym: Student alienation from physical education. Journal of Teaching in Physical Education, 4, 467-477.

Chase, R. (2000, June 07). Youth need more gym, less TV, researchers say. The Denver post, p. 8A.

Chen, A., \& Darst, P. W. (2001). Situational interest in physical education: A function of learning task design. Research Quarterly for Exercise and Sport, 72, 285-306. http://dx.doi.org/10.1080/02701367.2001.10608945

Child, D. (1990). The essentials of factor analysis ( $2^{\text {nd }}$ ed.). London: Cassel Educational Limited.

Chung, M., \& Phillips, D. A. (2002). The relationship between attitude toward physical education and leisure-time exercise in high school students. Physical Educator, 59, 126-138.

Colley, A., Comber, C., \& Hargreaves, D. J. (1994). Gender effects in school subject preferences: A research note. Educational Studies, 20, 13-18. http://dx.doi.org/10.1080/0305569940200102

Dunlavy, A. (2008). An Exploration of University Students' attitudes towards Physical Activity and the Importance of Physical Activity. Unpublished Master Thesis, University of Hawai'i, Honolulu, Hawai'i.

Figley, G. E. (1985). Determinants of attitudes toward physical education. Journal of Teaching in Physical Education, 4, 229-240.

Greenwood, M., \& Stillwell, J. (2001). Activity preferences of middle school physical education students. Physical Educator, 58, 26-29.

Hagger, M., Cale, L., \& Almond, L. (1995). The importance of children's attitudes towards physical activity. Kineziologija, 27, 12-16. 
Hagger, M. S., Chatzisarantis, N. L., \&. Biddle, J. H. (2002). A meta-analytic review of the theories of reasoned action and planned behaviour in physical activity: Predictive validity and the contribution of additional variable. Journal of Sport \& Exercise Psychology, 24, 3-32.

Iverson, D. C., Fielding, J. E., Crow, R. S., \& Christenson, G. M. (1985). The promotion of physical activity in the United States population: The status of programs in medical, worksite, community, and school settings. Public Health Reports, 100, 212-224.

Katz, D. (1960). The functional approach to the study of attitudes. Public Opinion Quarterly, 24, 163-204. http://dx.doi.org/10.1086/266945

Krouscas, J. A. (1999). Middle school students' attitudes toward a physical education program. Unpublished dissertation, Virginia Polytechnic Institute and State University, Blacksburg, Virginia.

Lee, A. M. (1997). Contribution of research on student thinking in physical education. Journal of Teaching in Physical Education, 16, 262-277.

Lee, A. M. (2004). Promoting lifelong physical activity through quality physical education. Journal of Physical Education, Recreation \& Dance, 75, 21-26. http://dx.doi.org/10.1080/07303084.2004.10607235

Liu, W., Wang, J., \& Xu, F. (2008). Middle school children's attitudes toward physical activity. The ICHPER.SD (The International Council for Health, Physical Education, Recreation, Sport \& Dance) Journal of Research, 3, 78-85.

Luke, M. D., \& Cope, L. D. (1994). Student attitudes toward teacher behavior and program content in school physical education. Physical Educator, 51, 57-66.

Luke, M., \& Sinclair, G. (1991). Gender difference in adolescent attitudes toward school physical education. Journal of Teaching in Physical Education, 11, 31-46.

McKenzie, T. L. (2003). Health-related physical education: Physical, activity fitness, and wellness. In S. J. Silverman \& C. D. Ennis (Eds.), Student learning in physical education: Applying research to enhance instruction (pp. 207-226). Champaign, IL: Human Kinetics.

Nelson, J. R., Thompson, J. K., \& Silverman, S. J. (2005). The survey. In A. Robertson, L.D. (Ed), Research methods in physical activity (pp. 269). Champaign, IL: Human Kinetics.

Olafson, L. (2002). "I hate phys. ed.": Adolescent girls talk about physical education. Physical Educator, Spring, $67-74$.

Papaioannou, A. (1994). Development of a questionnaire to measure achievement orientations in physical education. Research Quarterly for Exercise and Sport, 65, 11-20. http://dx.doi.org/10.1080/02701367.1994.10762203

Parkhurst, D. L. (2000). Comparison of attitudes toward physical activity and physical activity levels of sixth grade boys and girls of various ethnic origins. Microform Publications, University of Oregon. Retrieved from http://kinpubs.uoregon.edu

Patterson, P., \& Faucette, N. (1990). Attitudes toward physical activity of fourth and fifth grade boys and girls. Research Quarterly for Exercise and Sport, 61, 415-418. http://dx.doi.org/10.1080/02701367.1990.10607508

Portman, P. A. (1995). Who is having fun in physical education classes? Experiences of six grade students in elementary and middle schools. Journal of Teaching in Physical Education, 14, 445-453.

Raitakari, O. T., Juonala, M., \& Viikari, J. S. A. (2005). Obesity in childhood and vascular changes in adulthood: Insights into the Cardiovascular Risk in Young Finns Study. International Journal of Obesity, 29, S101-S104. http://dx.doi.org/10.1038/sj.ijo.0803085

Rikard, G. L., \& Banville, D. (2006). High school student attitudes about physical education. Sport, Education and Society, 11, 350-400.

Rink, J. (2006). Teaching physical education for learning ( $5^{\text {th }}$ ed.). New York: McGraw-Hill.

Sacker. A. (2005). Do adolescent leisure-time physical activities foster health and well-being in adulthood? Evidence from two British birth cohorts. The European Journal of Public Health 2006, 16, 331-335.

Silverman, S., \& Subramaniam, P. R. (1999). Student attitude toward physical education and physical activity: A review of measurement issues and outcomes. Journal of Teaching in Physical Education, 19, 97-125. 
Solmon, M. A. (2003). Student issues in physical education: Attitudes, cognition, and motivation. In S. J. Silverman and C. Ennis (Eds.). Student learning in physical education: Applying research to enhance instruction ( $2^{\text {nd }}$ ed.) (pp. 147-164). Champaign, IL: Human Kinetics.

Stucky-Ropp, R. C., \& DiLorenzo, T. M. (1993). Determinants of exercise in children. Preventive Medicine, 22, 880-889. http://dx.doi.org/10.1006/pmed.1993.1079

Subramaniam, P. R., \& Silverman, S. (2002). Using complimentary data: An investigation of student attitude in physical education. Journal of Sport Pedagogy, 8, 74-91.

Subramaniam, P. R., \& Silverman, S. (2007). Middle school students' attitudes toward physical education. Teaching and Teacher Education, 23, 602-611. http://dx.doi.org/10.1016/j.tate.2007.02.003

Tannehill, D., \& Zakrajsek, D. (1993). Student attitudes toward physical education: A multicultural study. Journal of Teaching in Physical Education, 13, 78-84.

U. S. Department of Health and Human Services. (2000). Healthy People 2010: Understanding and improving health $\left(2^{\text {nd }}\right.$ ed.). Washington, DC, U.S. Government Printing Office.

Valdez, L. A. (1997). Attitudes toward physical education of high school students and their parents. Unpublished doctoral dissertation, University of Southern California, Los Angles.

Zeng, Z. H. (2012). Attitudes of Students toward Physical Activities: High-school students' sports/physical activities preferences. LAP Lambert Academic Publishing AG \& Co. KG.

Zeng, Z. H., Leung, R. W., \& Hipscher, M. (2011). Attitudes of High School Students' toward Physical Education and Sport / Activities Preference. Journal of Social Science, 7, 529-537. http://dx.doi.org/10.3844/jssp.2011.529.537 